\title{
EVALUATION OF FACTORS THAT CONTRIBUTE TO OCCURRENCE OF ACCIDENTS AT CONSTRUCTION SITES IN NAIROBI COUNTY
}

\author{
George Otiki Makori \\ Faculty of Agriculture, Jomo Kenyatta University of Agriculture and Technology \\ P. O. Box 62000, 00200 Nairobi, Kenya \\ Corresponding Author email: otimakk@gmail.com \\ Prof. Edward George Mamati \\ Faculty of Agriculture, Jomo Kenyatta University of Agriculture and Technology \\ P. O. Box 62000, 00200 Nairobi, Kenya \\ Prof. John Bosco Njoroge \\ Faculty of Agriculture, Jomo Kenyatta University of Agriculture and Technology \\ P. O. Box 62000, 00200 Nairobi, Kenya \\ DOI: 10.31364/SCIRJ/v6.i8.2018.P0818544 \\ http://dx.doi.org/10.31364/SCIRJ/v6.i8.2018.P0818544
}

\begin{abstract}
:
In Kenya, the construction industry accounts for 5\% of the country's GDP and employs about 1 million people with an estimated annual wage bill of K.sh. 3.2 billion. Despite the highlighted gains of the sector, there are negative attributes associated with construction work as the International Labor Organization estimates at least 60,000 fatal accidents occur each year on construction sites around the world. There was hence a need to evaluate factors that contribute to occurrence of accidents at construction sites in order to avail much needed information that can help minimize accidents. Occurrence of accidents at building construction sites in Nairobi County was modelled against technical factors, skills, working environment, occupational health and safety practices. Thirty project sites were purposively sampled and evaluated. The respondents included supervisors, foremen, unskilled/skilled employees, government officers and site developers. A regression and correlation analysis was used in the study. Findings of the survey indicated that technical factors as well as working environment were negatively and insignificantly related to occurrence of accidents, while skills and occupational safety practices were significantly related to occurrence of accidents. It was established that that technical factors, inclusion of regular maintenance of construction equipment in the standard conditions of contract at the site, quality inspection of projects and conducting regular checks so as to detect and correct faults, significantly reduced occurrence of accidents. The results also revealed that an increase in the frequency of regular checks at the site to ensure that safe methods of work are employed, thorough audit of the abilities of contractors before they are given a contract, frequent skill audit at the site to ensure that workers have the required skills to execute work safety and conducting of trainings on the personnel and workers at the construction site in order to raise their awareness and technical knowhow on their jobs leads to a reduction in occurrence of accidents at construction sites. The findings also revealed that provision of safety gear at the site to protect workers against continuous exposure to moderately high level of impulse noise such as explosives on site noise produced by heavy equipment, welding noise etc. to prevent occupational deafness, provision of guard railing systems or other alternatives at the site to prevent mechanical hazards, construction workers at the site working under sheltered environment to avoid adverse weather conditions which could lead to discomfort and illness, optimizing of the size of workforce given the available working space and technology so as to avoid cases of over deployment in order to minimize accidents leads to a significant decrease in occurrence of accidents at construction sites. The study findings also showed that regulation of safety risk assessment by OHS and the government of Kenya, regulation of safety risk planning before approval of building plans, presentation of safety risk plan as a condition before development of a building and development of standards of acceptable building densities (ratio of building are to plot size) for various categories of construction projects in Kenya leads to a reduction in occurrence of accidents at construction sites in Kenya. The study recommends for a need to have better working conditions at construction sites, employees to have the required technical skills, the construction sites management to ensure adherence to occupational and safety standards in order to reduce occurrence of accidents at the construction sites in Kenya.
\end{abstract}

Index Terms: Technical Factors, Occupational Safety, Skills, Work Environment, and Occurrence of Accidents 


\section{Introduction}

Construction' comprises of all civil engineering works, all types of building works (including but not restricted to housing), as well as the maintenance and repair of existing facilities (Wells, 1985).Various studies for instance, Pheng and Leong, (1992); Wells, (2001) and, Giang and Pheng (2011) have demonstrated that there is a significant and positive relationship between construction industry outputs and the economic growth of developing countries. Ofori (2006) argues that construction in developing countries contributes a big share of capital formation as well as national income. Besides investments in new factories, machinery, equipment and materials, investment in construction infrastructure including civil works such as roads, dams, water and drainage facilities, and buildings increases the physical capital of a nation and thus, expands the national output level (Giang and Pheng, 2011). The importance of construction in developing countries can thus not be underestimated.

Mike et al (2011) argues that by 2020 construction will account for $13.2 \%$ of world GDP indicating an upward trend. This is seen in the provision of basic infrastructure such as road networks, commercial and residential buildings and facilities to the other sectors of economies. Also construction's sizeable amount of economic growth is through backward and forward linkages since construction activities utilize goods and services from other industries. Employment creation by construction activities is another important aspect in economic development. In the Kenyan's economy construction industry accounts for 5\% of the country's GDP and employs about 1 million people with an estimated annual wage bill of K.sh. 3.2 billion (KNBS, 2012).

Despite the highlighted gains of the sector, there are negative attributes associated with construction work. Construction work is dangerous; the International Labor Organization (ILO) estimates that at least 60,000 fatal accidents occur each year on construction sites around the world that is one in six of all fatal work related accidents. The global trade union federation puts the figure much higher at 108,000 with construction responsible for $30 \%$ of all work related accidents. Stated differently, one fatal accident occurs every ten minutes (LopezValcarcel, 2001).

Due to the increased number of accidents, ILO in an effort to improve and maintain safe working environment at work places has held severe conferences through the years since 1937 deciding and adopting conventions and recommendations geared towards health and safety in construction works. One such is convention; C167 cited as the Safety and Health in Construction Convention, 1988 was revised and adopted the Safety Provisions (Building) Convention of 1937 (Wilson et al , 2007).

Kakitahi et al. (2013) highlighted some of the factors influencing the occurrence of construction site accidents; some of the determinants are rework due to poor quality work and insufficient skilled labor that result in rework during the construction and operation stages of buildings. Lubega et al. (2000) indicate inadequate supervision, use of incompetent personnel and the use of inadequate construction techniques. Regarding the building industry, in particular, the collapse of building elements and improper use of machinery cause most of the fatalities, while workers being hit by Objects and falls are the most common causes of major injuries on building sites (Alinaitwe et al., 2007). Jaselskis and Suazo (1994) demonstrated a substantial lack of awareness or importance for safety at all levels of the construction industry. In addition, Laufer and Ledbetter (1986) assessed various safety measures. The current study sought to evaluate the factors that contribute to occurrence of accidents at construction sites in Kenya.

\section{Statement of the problem}

Construction work is considered to be one of the most hazardous industrial activities in the world (Kadiri et al, 2014). Every year many people fall victim to injury, harm and even death caused by accidents on construction sites. Statistics indicate that there has been a rise in accidents in construction sites by $20 \%$ in Kenya since the year 2011 (Gichuhi, 2013). An example of one particular accident is a building under construction which collapsed in Zimmerman in the year 2015 (Wachira, 2015).

Precautionary measures to control accidents in the building industry are vital. Employers are required to assess risk and take practical measures to protect, ensure safety and health of their workers, minimizing risk by means of continuous surveillance and monitoring of where accidents are likely to occur (Odetoyinbo, 1986). In order to understand the control measures, major factors that contribute to occurrence of accidents in the building industry in Kenya must be identified.

Research on occurrence of accidents in building industry is scant and inconclusive. Kakitahi et al.(2013), Lubega et al. (2000), Alinaitwe et al.(2007), Mwakali, 2006) and Lopez et al.(2008) investigated the factors influencing the occurrence of construction site accidents. These studies however focused on other contexts other than construction sites in Nairobi County thus presenting contextual knowledge gaps. The determinants of construction sites accidents in the different contexts might not apply to the Kenyan and specifically, Nairobi context hence the importance of this study to focus on Nairobi County.

\section{Research Objectives}

I. To establish the influence of technical factors and skills on occurrence of accidents at construction sites in Nairobi County

II. To determine the influence of working environment on occurrence of accidents at Construction sites in Nairobi County.

III. To evaluate influence of occupational health and safety practices on occurrence of accidents at Construction sites in Nairobi County. 


\section{Literature Review}

\section{Domino Theory}

Heinrich developed the domino theory (model) of causation that suggests five dominoes namely ancestry and social environment, fault of a person, unsafe acts and condition, accident, and injury. This five dominoes model suggested that through inherited or acquired undesirable traits, people may commit unsafe acts or cause the existence of mechanical or physical hazards that result in injury (Abdelhamid and Everett, 2000). This theory has pointed to two main things; first, people are the fundamental reason of caused accident. Using a worker to carry out a job they are not trained to do leads to the occurrence of most accidents. Secondly, the management should be responsible for the accident prevention. The management should provide workers with safety facilities to prevent the workers from hazardous environment.

The domino theory has been criticized for emphasizing human behavior in causing accidents (Zeller, 1986) and for assuming that the cause-effect relation between consecutive events is linear and deterministic (Qureshi, 2007). Over the years, the domino theory has been updated to focus on management responsibility for accidents. The resulting models are called management models or updated domino models. Despite its simplicity, the domino theory is the foundation of other theories including human error theories, epidemiological theories and systems theories, amongst others.

\section{Multiple causation theory}

The theory was introduced by Petersen as caution against narrow interpretations of the domino theory (Petersen, 1971). The multiple causation theory suggests that there are many contributing factors to every accident and that these factors combine together in a random fashion causing accidents (Petersen, 1971; 1988). These are the factors that should be targeted by an accident investigation (Petersen, 1971; 1988). The multiple causation theory suggests that root causes of most accidents are often related to management policies and procedures, supervision or training (Petersen, 1988). The theory is relevant to the study as it guides the selection of study variables. The theory suggests that many factors that contribute to every accident combine together to cause major accidents. As the study seeks to establish the factors contributing to construction site accidents, the theory comes in handy in the Kenyan context.

\section{Human Error Theories}

Human error theories acknowledge the contribution of human errors to accidents occurrence. They are commonly classified as behaviour models and human factor models (Abdelhamid and Everett, 2000). Human factor models hold that human error is the main cause of accidents. However, the blame does not fall on the human unsafe characteristics alone but also on the design of the workplace and tasks that do not consider human limitations, and may therefore have harmful effects (Abdelhamid and Everett, 2000). The overall objective of the human factors approach is to arrive at better designed tasks, tools and work places, while acknowledging the limitations of humans' physical and psychological capabilities (Abdelhamid and Everett, 2000).

\section{Conceptual Framework}

- Technical Factors

- $\quad$ Skills

- Working Environment

- Occupational Health and Safety practices

Occurrence of accidents at construction sites in Nairobi

\section{Independent Variable}

Dependent Variable

\section{Figure 1 Conceptual Framework}

\section{Technical Factors}

Technical factors involving handling of machines and equipment can influence the occurrence of accidents at construction sites. Irumba (2015) argues that provisions for regular maintenance of construction equipment should be included in the standard conditions of contract. Irumba (2015) made this recommendation based on the findings of a study he conducted which indicated that occurrence of accidents on buildings sites in Kampala is dependent on the condition of safety equipment.

\section{Skills}

If employees are to make the maximum contribution to safety and health, adequate arrangements must be in place to ensure that they have the necessary skills to do their work safely. This means more than simply training. Application of skills and knowledge is an important ingredient and needs to be gained under adequate supervision. Managers should know the relevant legislation and be able to manage safety and health effectively. All employees need to be able to work in a safe and healthy manner. It is also necessary to check the pool of skills of contractors where they work close to, or in collaboration with, direct employees (Jimmie, 2001). The level of skills of employees can influence occurrence of accidents at construction sites. Hinze and Wilson (2000) argued that that frequency of injuries depends on employees' turnover. 


\section{Working Environment}

The company should be committed to providing a safe and healthy work environment that meets or exceeds the standards of the Provincial Occupational Health and Safety Act, Regulation and Code with a purpose of protecting employees, visitors, subcontractors, clients, company property and the environment (Adeniye, 2001).

Adeniye (2001) further points out that working conditions matters a lot in as far as occurrence of accidents is concerned. According to him, since construction workers work on unsheltered environment, adverse weather conditions should be avoided because continuous exposure to adverse weather could lead to general discomfort and illness. Continuous exposure to moderately high noise level or relatively high level of impulse noise such as explosives on site, noise produced by heavy equipment, welding noise , are major causes of occupational deafness.

\section{Occupational Health and Safety Practices}

The protection of the health and safety of all employees through training is vital to the success of all organizations. Poor occupational health and safety (OSH) performance can take a heavy financial toll on any business, not to mention the human cost of work-related illness, injury, and fatality. Maina (2014) argues that in relation to OSH, the law exists to indemnify the responsibility of the parties involved in industrial or commercial activities and here construction in particular. It improves responsibilities of the employers to protect the health and safety of their employees when they are at work and protects the right of the people to participate in the paid workforce without suffering injury or ill health as a result.

Adherence to quality assurance measures has an effect on occurrence of accidents at construction sites. Haupt (2003) argues that construction works remains the most dangerous place to work. According to him, during the last three decades, safety and health regulation were revised in many countries. Some new laws and regulation methods changed existing laws. According to David (1998), small companies constitute the most part of construction industry nowadays. David (1998), states that there is a tendency, that organizing processes must be improved in these companies in order to secure worker's safety and health. For that reason, the financial help is essential. Also there is a suggestion for European countries to adopt the standard from Great Britain.

\section{Empirical Review}

A study was conducted in Uganda by Irumba (2015) whose main aim was to propose strategies and policies for improvement of the performance of the construction industry (including housing) in Uganda. The findings of the study indicated that occurrence of accidents on buildings sites in Kampala is dependent on the availability of safety equipment. The findings further indicated that occurrence of accidents on buildings sites in Kampala is dependent on the condition of safety equipment. A study was conducted by the Construction Industry Research and Policy Center at the University of Tennessee, Knoxville for OSHA's Office of Statistics (2011). In order to inspect fatal events in construction during the 2003 this group implemented univariate frequency analysis. Fall from/through roof led all other causes in number of fatal events (76 or $10.7 \%$ of total fatal events), followed by fall from/with structure (74 or $10.5 \%$ ). The third leading cause was crushing/run-over of non-operators by operating construction equipment $(7.9 \%)$; followed by electrocution by equipment contacting wire (6.6\%); electric shock from equipment installation/tool use $(6.1 \%)$; and trench collapse $(5.8 \%)$. In Nigeria, Kadir et.al (2014) conducted a study to examine the major causes of accidents and suggested ways of mitigating these accidents on construction sites. The findings indicated that negligence is the main cause of accidents on construction sites in Nigeria, laborers are also the major victims of these site accidents, loss of time in project execution is the major effect caused by these accidents in project execution.

Rahmani et al (2013) conducted a descriptive study of occupational accidents and their causes among electricity distribution company workers over eight-year period in Iran. It was established that most of the accidents occurred in summer, and 51.3\% were during shift work. Worker negligence (malpractice) was the cause of $75 \%$ of deaths. Type of employment had a significant relationship with type of injuries $(\mathrm{p}<0.05)$. Most injuries were electrical burns. Huang and Hinze (2003) conducted a study on construction worker fall accidents. The result showed that most fall accidents took place at elevations of less than 9.15m, occurring primarily on new construction projects of commercial buildings and residential projects of relatively low construction cost. Jannadi and Bu-Khamsin (2002) conducted a study on safety factors considered by industrial contractors in Saudi Arabia. The study concluded that safety rules and regulations not only overcome issues like poor quality work, unsafe working conditions, and lack of environmental control but also reduce cost and enhance productivity. Wilson Jr. and Koehn (2002) suggested that safety practices vary with construction sites, as every site has unique safety aspects. Larger construction projects are better organized whereas small to medium firms do not have adequate safety program or person to oversee safety criteria. Gillen $e t$. al. (2002), in their study titled, "injured construction workers' perceptions of workplace safety climate, psychological job demands, decision latitude, and coworker support, and the relationship of these variables", used several questionnaires involving these variables. Based on the survey, the authors found significant positive correlation between injury severity and the safety climate scores, and between the safety climate scores and union status.

\section{Research Methodology}

This study employed descriptive survey design. The study conducted a survey of 30 construction sites in all the economic zones in Nairobi County to avoid bias. The construction sites were surveyed at Dandora, Huruma, Kahawa West, Kasarani, Runda and Karen. The study considered the following types of construction projects namely; flats, bungalows, maisonettes and high rise commercial buildings. The sampling frame consisted of the supervisors, foremen, government OSHA officers and contractors. From 30 construction sites, the total number of supervisors was 120, foremen were 120, OSH officers were 6 and contractors 
were 30 making a population of 276 respondents. From a total of 276 respondents, a total of ninety six people were interviewed. Quantitative data was collected through structured questionnaires. Qualitative data was collected using the interview guide. Both descriptive and inferential statistics were used for analysis. Descriptive analysis included frequencies, percentages, mean and standard deviation. They were presented in form of tables and charts. A multiple linear regression model was used to test the significance of the factors that contribute to occurrence of accidents at the building construction sites in Nairobi County. The multiple linear regression model is as laid below.

$\mathrm{Y}=\alpha+\beta 1 \mathrm{X} 1+\beta 2 \mathrm{X} 2+\beta 3 \mathrm{X} 3+\beta 4 \mathrm{X} 4+e$, Where: $\mathrm{Y}=$ Occurrence of accidents; $\mathrm{X} 1=$ Technical factors; $\mathrm{X} 2=\mathrm{Skills} ; \mathrm{X} 3=$ Working environment, $\mathrm{X} 4=$ Occupational health and safety practices $\mathrm{e}=$ Error term and $\alpha=$ constant, $\beta=$ coefficient of independent variables

\section{Results and Discussion}

The number of questionnaires that were administered was 96 . A total of 89 questionnaires were properly filled and returned. This represented an overall successful response rate of $92.70 \%$ which according to Babbie (2004) is rated as very good.

Influence of technical factors on accident occurrence

Table 1: Influence of technical factors on accident occurrence

\begin{tabular}{llllll} 
Statement & $\mathbf{1}$ & $\mathbf{2}$ & $\mathbf{3}$ & $\mathbf{4}$ & $\mathbf{5}$ \\
\hline $\begin{array}{l}\text { There is inclusion of provisions for } \\
\text { regular maintenance of construction } \\
\text { equipment in the standard conditions of } \\
\begin{array}{l}\text { contract at the site } \\
14.30 \%\end{array}\end{array}$ & $26.20 \%$ & $3.60 \%$ & $40.50 \%$ & $15.50 \%$
\end{tabular}

Quality inspection of projects has been strengthened at the site and is being conducted regularly so as to detect and correct faults early before they lead to accidents

$\begin{array}{lllll}2.20 \% & 30.30 \% & 14.60 \% & 38.20 \% & 14.60 \%\end{array}$

There is regular testing of materials at the site so as to detect and correct faults early before they lead to accidents

$\begin{array}{lllll}5.60 \% & 18.00 \% & 32.60 \% & 32.60 \% & 11.20 \%\end{array}$

There is regular testing and calibration of construction equipment's at the site so as to detect and correct faults early before they lead to accidents

$\begin{array}{lllll}3.40 \% & 44.90 \% & 10.10 \% & 32.60 \% & 9.00 \%\end{array}$

Plans and mechanisms have been put in place at the site to reduce the duration taken to detect rework at the site so as to prevent accidents resulting from reworks

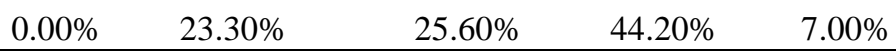

The results presented in Table 1 indicate that $55.5 \%$ there was inclusion of provisions for regular maintenance of construction equipment in the standard conditions of contract at the site, $52.8 \%$ of the respondents agreed that quality inspection of projects has been strengthened at the site and is being conducted regularly so as to detect and correct faults early before they lead to accidents,43.8 agreed that there is regular testing of materials at the site so as to detect and correct faults early before they lead to accidents, $41.6 \%$ agreed that there is regular testing and calibration of construction equipment at the site so as to detect and corrects faults early before they lead to accidents and $51.2 \%$ of the respondents were in agreement that plans and mechanisms have been put in place at the site to reduce the duration taken to detect rework at the site so as to prevent accidents resulting from rework.

The results imply that inclusion of provisions for regular maintenance of construction equipment in the standard conditions of contract at the site had the highest rating followed by quality inspection of projects at the site so as to detect and correct faults 
early before they lead to accidents the putting in place plans and mechanisms to reduce the duration taken to detect rework at the site so as to prevent accidents resulting from rework. The least practiced activities were regular testing of materials at the site so as to detect and correct faults early before they lead to accidents as well as regular testing and calibration of construction equipment at the site so as to detect and corrects faults early before they lead to accidents.

\section{Influence of Skills on accident occurrence}

Table 2: $\quad$ Influence of Skills on accident occurrence

\begin{tabular}{lllllll}
\hline Statement & $\mathbf{1}$ & $\mathbf{2}$ & $\mathbf{3}$ & $\mathbf{4}$ & $\mathbf{5}$ \\
\hline $\begin{array}{l}\text { There is regular checks at the site to ensure } \\
\text { that safe methods of work are employed }\end{array}$ & & & & & \\
& $3.50 \%$ & $20.90 \%$ & $24.40 \%$ & $44.20 \%$ & $7.00 \%$
\end{tabular}

There is frequent skill audits at the site to ensure that workers have the required skills to execute work safely

$\begin{array}{lllll}9.30 \% & 30.20 \% & 17.40 \% & 38.40 \% & 4.70 \%\end{array}$

The construction workers and personnel on site are often trained in order to raise their awareness

$\begin{array}{lllll}0.00 \% & 41.70 \% & 13.10 \% & 26.20 \% & 19.00 \%\end{array}$

There is a thorough audit of the abilities of contractors before they are given a contract

$0.00 \% \quad 20.90 \% \quad 20.90 \% \quad 40.70 \% \quad 17.40 \%$

The results presented in Table 2 indicates that $51.2 \%$ of the respondents agreed that there are regular checks at the site to ensure that safe methods of work are employed, $43.1 \%$ were in agreement that there is frequent skill audit at the site to ensure that workers have the required skills to execute work safety, $45.2 \%$ agreed that that construction workers and personnel on site are often trained in order to raise their awareness. The findings also indicated that $58.1 \%$ of the respondents believe there is thorough audit of the abilities of contractors before they are given a contract.

The findings indicate that the regular checks at the site to ensure that safe methods of work are employed had the highest rating followed by thorough audit of the abilities of contractors before they are given a contract. The practices which are least practiced are training of the site operators in order to raise their awareness as well as frequent skill audit at the site to ensure that workers have the required skills to execute work safety.

\section{Influence of working environment on accident occurrence}

Table 3: $\quad$ Influence of working environment on accident occurrence

\begin{tabular}{llllll}
\hline Statement & 1 & 2 & 3 & 4 & 5 \\
\hline
\end{tabular}

There is provision of gears at the site to protect workers against continuous exposure to moderately high noise level or relatively high level of impulse noise such as explosives on site, noise produced by heavy equipment, welding noise etc. to prevent occupational deafness.

$\begin{array}{lllll}10.8 \% & 19.30 \% & 34.90 \% & 31.30 \% & 3.60 \%\end{array}$

There is provision of guard railing systems or other alternatives at the site to prevent mechanical hazards

$2.30 \% \quad 26.70 \% \quad 31.40 \% \quad 34.90 \% \quad 4.70 \%$

Construction workers at the site work under sheltered environment to avoid adverse weather conditions which could lead to discomfort and illness 
Mechanisms for optimization of the size of workforce given the available working space have been set at the site to avoid cases of over deployment in order to minimize accidents

$3.70 \% \quad 42.70 \% \quad 19.50 \% \quad 34.10 \% \quad 0.00 \%$

Mechanisms for optimization of the size of workforce given the available technology have been set at the site to avoid cases of over deployment in order to minimize accidents $\begin{array}{lllll}3.50 \% & 22.10 \% & 39.50 \% & 26.70 \% & 8.10 \%\end{array}$

The results presented in Table 3 on working environment indicates that $34.9 \%$ of the respondents agreed that there is provision of gears at the site to protect workers against continuous exposure to moderately high level of impulse noise such as explosives on site, noise produced by heavy equipment, welding noise etc. to prevent occupational deafness. $39.6 \%$ were in agreement that there is provision of guard railing systems or other alternatives at the site to prevent mechanical hazards. Construction workers at the site work under sheltered environment to avoid adverse weather conditions which could lead to discomfort and illness this was agreed upon by $15.1 \%$ of the respondents.34.1\% agreed that mechanisms of optimization of the size of workforce given the available working space have been set at the site to avoid cases of over deployment in order to minimize accidents and $34.8 \%$ agreed that mechanisms of optimization of the size of workforce given the available technology have been set at the site to avoid cases of over deployment in order to minimize accidents.

The findings indicate that practices involving conditioning against work environment were least practiced as compared to other factors. Provision of gears at the site to protect workers against continuous exposure to moderately high level of impulse noise as well as provision of guard railing systems was less practiced. Working under sheltered environment to avoid adverse weather conditions which could lead to discomfort and illness was the least practiced.

Influence of Occupational and safety practices on accident occurrence

Table 4: $\quad$ Influence of Occupational and safety practices on accident occurrence

\begin{tabular}{llllll}
\hline Statement & $\mathbf{2}$ & $\mathbf{2}$ & $\mathbf{3}$ & $\mathbf{4}$ & $\mathbf{5}$ \\
\hline $\begin{array}{l}\text { Safety risk planning has been regulated } \\
\text { by OHS }\end{array}$ & $13.50 \%$ & $19.10 \%$ & $19.10 \%$ & $41.60 \%$ & $6.70 \%$ \\
$\begin{array}{l}\text { Safety risk assessment has been regulated } \\
\text { by OHS }\end{array}$ & $3.60 \%$ & $26.50 \%$ & $15.70 \%$ & $49.40 \%$ & $4.80 \%$ \\
$\begin{array}{l}\text { Before approval of building plans by the } \\
\text { relevant authorities, safety risk plans are } \\
\text { presented as a condition }\end{array}$ & $3.50 \%$ & $31.40 \%$ & $27.90 \%$ & $25.60 \%$ & $11.60 \%$ \\
$\begin{array}{l}\text { Standards of acceptable building } \\
\text { densities (Ratio of building area to }\end{array}$ & & & & & \\
\end{tabular}

plot size) have been developed for various categories of construction projects in Kenya

The government of Kenya has collaborated with professional bodies in development of guidelines of implementing safety programmes to be used at construction sites

$\begin{array}{lllll}6.70 \% & 15.70 \% & 21.30 \% & 28.10 \% & 28.10 \%\end{array}$

The results on occupational and safety practices indicate in Table 4 reveal that $48.3 \%$ of the respondents agreed that safety risk planning has been regulated by OHS, $54.2 \%$ of them also agreed that safety risk assessment has been regulated by OHS. Before approval of building plans the relevant authorities, safety risk plan are presented as a condition this is according to37.2\% of the respondents.44.9\% agreed that standards of acceptable building densities (ratio of building are to plot size) have been developed for various categories of construction projects in Kenya and 56.2\% were in agreement that the government of Kenya has collaborated with professional bodies in development of guidelines of implementing safety programmes to be used at construction sites. 
The findings imply that the government of Kenya collaborating with professional bodies in development of guidelines of implementing safety programmes to be used at construction sites received the highest rating followed by safety risk assessment being regulated by OHS. The other factors such as safety risk planning being regulated by OHS, safety risk plan being presented as a condition to the relevant authorities before approval of building plans and development of standards of acceptable building densities (ratio of building are to plot size) for various categories of construction projects in Kenya received lower ratings.

\section{Rate of Occurrence of accidents}

The study sought to generally establish the occurrence of accidents in the building industry in Nairobi. The respondents were requested to indicate their agreement or disagreement with statements regarding regulatory requirements. The descriptive results are presented in Table

4.7.

Table 5: Rating on Occurrence of accidents

\begin{tabular}{|l|l|l|l|l|l|}
\hline Statement & $\mathbf{1}$ & $\mathbf{2}$ & $\mathbf{3}$ & $\mathbf{4}$ & $\mathbf{5}$ \\
\hline $\begin{array}{l}\text { The proportion of occupational deafness at } \\
\text { the construction site has reduced }\end{array}$ & $0.00 \%$ & $13.50 \%$ & $49.40 \%$ & $30.30 \%$ & $6.70 \%$ \\
\hline $\begin{array}{l}\text { The proportion of death caused by } \\
\text { construction accidents has decreased }\end{array}$ & $2.20 \%$ & $23.60 \%$ & $16.90 \%$ & $47.20 \%$ & $10.10 \%$ \\
\hline $\begin{array}{l}\text { The proportion of fall from heights } \\
\text { accidents at the construction site has } \\
\text { decreased }\end{array}$ & $4.50 \%$ & $12.40 \%$ & $18.00 \%$ & $38.20 \%$ & $27.00 \%$ \\
\hline
\end{tabular}

The results presented in Table 5 indicate that $37 \%$ of the respondents agree that the number of occupational deafness at the construction site has reduced, 57.3\% agree that the number of death caused by construction accidents has reduced and $65.2 \%$ of the respondents were in agreement that the number of fall from heights accidents from the construction site has decreased.

\section{Determinants of occurrence of accidents at construction sites in Nairobi County}

The study used Pearson correlation analysis to establish the determinants of accidents at construction sites in Nairobi County. The data collected was from likert scale responses which gave quantitative data. The scholar who developed likert scale, Likert (1932), argued that parametric tests can be used to analyze Likert scale responses when they are converted to a total score or mean score for the scale items. According to Likert (1932), parametric analysis of ordinary averages of Likert scale data is justifiable by the Central Limit Theorem. The data in this study was converted to mean scores to allow parametric analysis such as correlation and regression to be conducted. Similar methods have been applied by studies by Irumba (2015) whose main aim was to propose strategies and policies for improvement of the performance of the construction industry (including housing) in Uganda ; Kadir et.al (2014) who conducted a study to examine the major causes of accidents and suggested ways of mitigating these accidents on construction sites as wellas Rahmani et al (2013) who conducted a descriptive study of occupational accidents and their causes among electricity distribution company workers over eight-year period in Iran. This study was henc e justified in the approach. The results for correlation analysis are presented in Table 6.

Table 6: Determinants of occurrence of accidents

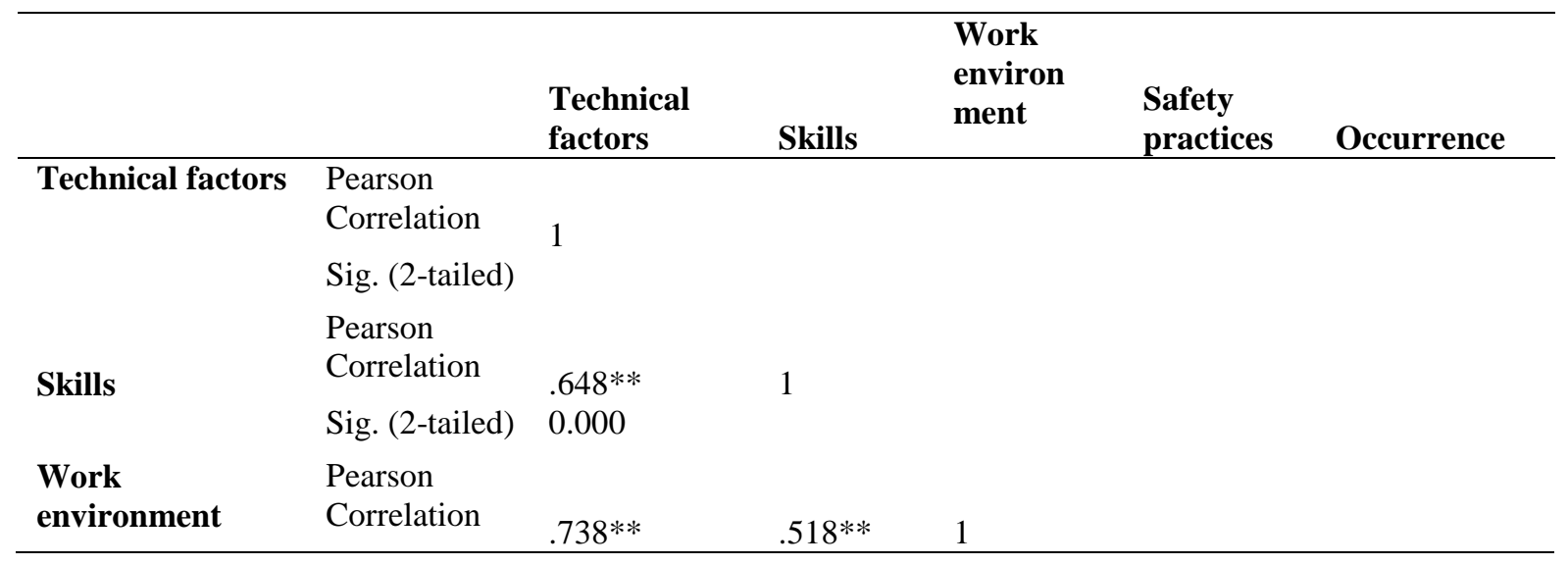




\section{Sig. (2-tailed) $\quad 0.000 \quad 0.000$}

\section{Safety practices Pearson}

Correlation

$.649 * *$

$.747 * *$

Sig. (2-tailed) 0.000

0.000

$.500 * *$

1

Pearson

Occurrence of

Correlation

Accidents

Sig. (2-tailed) $\quad 0.491$

$-0.18$

0.000

$0.040 * *$

$-0.118$

$-.276^{* *}$

0.009

** Correlation is significant at the 0.01 level (2-tailed).

The findings indicate that there is a negative association between technical factors and occurrence of accidents at construction sites in Nairobi County. The association is however not significant ( $p$-value $=0.491$ ). This means that in explanation of determinants of occurrence of accidents, technical factors is not among the key determinants. The findings also indicate that there is a negative and significant association between skills and occurrence of accidents in the study area $(\mathrm{P}-\mathrm{Value}=0.04)$. This means that in explanation of determinants of occurrence of accidents, skills is among the main causes of accidents. The findings imply that an increase in the workers experience of applying skills and knowledge is associated with a decrease in occurrence of accidents at construction sites in Nairobi County.

The study findings also indicate that there is a negative and significant association between safety practices and occurrence of accidents in the study area ( $\mathrm{p}$-value $=0.009$ ). The findings imply that an increase in the workers experience of applying skills and knowledge is associated with a decrease in occurrence of building accidents. Work environment was found to be negatively associated with occurrence of accidents at construction sites in Nairobi County. The association is however not significant (pvalue $=0.280$ ). This means that in explanation of determinants of occurrence of accidents, work environment is not among the key determinants. A regression model was also used to establish the determinants of occurrence of accidents at Construction sites in Nairobi County. A regression model shows not only the direction of the effect but also the magnitude of the effect. That is why it was suitable for this study. The results in Table 7 indicate the model summary.

Table 7: Model Summary

\begin{tabular}{llll}
\hline $\mathbf{R}$ & R Square & Adjusted R Square & Std. Error of the Estimate \\
\hline-.485 & 0.235 & 0.196 & 0.6893 \\
\hline
\end{tabular}

The model summary indicates that the joint predictor variables (technical factors, working environment, occupational safety practices and skills) are negatively associated with occurrence of accidents at construction sites in the study area within Nairobi County $(\mathrm{R}=-\mathbf{0 . 4 8 5})$. The coefficient of determination, $\mathrm{R}$ square of 0.235 , indicated that the joint predictor variables (technical factors, working environment, occupational safety practices and skills) explain up to $23.5 \%$ of the changes in occurrence of accidents at construction sites in Nairobi County $(\mathrm{R}$ square $=0.235)$. The remaining $76.5 \%$ is explained by other factors. The results for model fitness are as presented in Table 8.

Table 8: $\quad$ Model Fitness

\begin{tabular}{|c|c|c|c|c|c|}
\hline & Sum of Squares & df & Mean Square & $\mathbf{F}$ & Sig. \\
\hline Regression & 11.4 & 4 & 2.85 & 5.998 & .000 \\
\hline Residual & 37.062 & 78 & 0.475 & & \\
\hline Total & 48.462 & 82 & & & \\
\hline
\end{tabular}

The model fitness results indicate that the null hypothesis that the model did not fit was rejected at 5\% level of significance since the p-value was significant $(\mathrm{p}$-value $=0.000$ ). This implies that the model fitting the four predictor variables technical factors, working environment, occupational safety practices and skills to occurrence of accidents fit well. The coefficients are as indicated in Table 9.

Table 9: $\quad$ Model coefficients

\begin{tabular}{llccc}
\hline Indicator & B & Std. Error & t & Sig. \\
\hline & \multicolumn{2}{c}{ www.scirj.org }
\end{tabular}




\begin{tabular}{lllll}
\hline (Constant) & 4.739 & 0.337 & 14.07 & 0.000 \\
Technical factors & -0.07 & 0.113 & -0.618 & 0.538 \\
Skills & -0.162 & 0.086 & -2.896 & 0.042 \\
Working environment & -0.015 & 0.103 & -0.143 & 0.887 \\
Safety practices & -0.301 & 0.095 & -3.171 & 0.002 \\
\hline
\end{tabular}

The regression results indicate that technical factors are negatively related to occurrence of accidents at the selected construction sites in Nairobi County (beta $=0.07$ ). The relationship is however not significant $(\mathrm{P}$-value $=0.538$ ). The findings also indicate that working environment is negatively related to occurrence of accidents at the selected construction sites within the study area of Nairobi County (beta $=-0.015$ ). This implies that an improvement in the working conditions decreases the occurrence of accidents at construction sites in Nairobi County. The relationship is however not significant ( $\mathrm{p}$ value $=0.887$ ). This implies that the factor is not significant in explaining occurrence of accidents at construction sites within the study area of Nairobi County.

The study findings agrees with Irumba (2015) that occurrence of accidents on buildings sites in Kampala is more dependent on the condition of safety equipment. The findings also agree with Sawacha, et. al. (1999) who indicated that among the variables that were found to be significant in causing accidents in building industry is ongoing safety training. The findings agree with that of Adeniye (2001) who indicated that working conditions matters a lot in as far as occurrence of accidents is concerned. According to him, since construction workers work on unsheltered environment, adverse weather conditions should be avoided because continuous exposure to adverse weather could lead to general discomfort and illness. Continuous exposure to moderately high noise level or relatively high level of impulse noise such as explosives on site, noise produced by heavy equipment and welding noise, are major causes of occupational accidents. The findings also agree with the findings of a study by Hassanein \& Hanna (2008) that the main causes of accidents in the building industry are working on a scaffold or platform without guard rails, or without a safety harness correctly attached, and fragile roofs and ladders that are badly maintained, positioned, and secured. Slips, trips, and falls are the largest cause of accidents in all sectors.

The findings also indicate that workers skills and experience in handling machines is negatively and significantly related to occurrence of accidents at construction sites within the study area of Nairobi County (beta $=0.162, \mathrm{p}$ value $=0.042$ ). This implies that the more the workers acquire necessary skills and experience to do their work, the more there is reduction of occurrence of accidents at construction sites in Nairobi County. A one unit increase in the workers rate of acquiring the necessary skills and experience through among other means training by the management, leads to a 0.162 decrease in occurrence of accidents at construction sites within the study area of Nairobi County. The findings are consistent with the findings of a study by Rahmani et al (2013) which concluded that high rate of accidents in summer may be due to the warm weather or insufficient professional skills in seasonal workers. The findings however don't agree with the findings of a study by Sawacha, et. al. (1999) which found out that among the determinants of accidents in the building industry, job experience and skills was significant.

Further findings indicate that occupational safety practices is negatively and significantly related to occurrence of accidents in the building industry (beta $=0.301$, $\mathrm{p}$ value $=0.002$ ). This implies that the more the occupational safety and health practices are put in place, the more there is a reduction in occurrence of accidents in the building industry. The findings imply that a one unit increase in the frequency of practicing occupational safety leads to a 0.301 decrease in the occurrence of accidents at the building construction sites within the study area of Nairobi County. The findings agree with those of Irumba (2015) which showed that occurrence of accidents on buildings sites in Kampala was dependent on the availability of safety equipment. The findings also agree with Jannadi and Bu-Khamsin (2002) who concluded that safety rules and regulations not only overcome issues like poor quality work, unsafe working conditions, and lack of environmental control but also reduce cost and enhance productivity. Furthermore, the findings agree with Sawacha, et. al. (1999) who found out that among the variables that were found to be significant in causing accidents in building industry were the impact of Health and Safety act.

The quantitative findings were also supported by qualitative results. On whether there was experience of occurrence of accidents related to technical factors, $79 \%$ of the respondents agreed that that there was occurrence of accidents. This was attributed to machine failure due to overload and limited inspection and checkups on the machines. Furthermore, $72 \%$ indicated that they don't experience cases of accidents because the management ensures safety of all and conducts regular tests and maintenance of all the machines they use. The respondents indicated that they do experience accidents as a result of improper placement because most of the employers employ inexperienced workers in order to pay them less amount as compared to what a qualified employee would have demanded and that contributes to accidents. Those who cited lack of measures put in place to minimize accidents as a result of improper placement since the main focus is cutting costs in form of poor pay were $39 \%$. On the other hand, regarding occurrence of accidents due to poor working conditions, $79 \%$ of the respondents indicated that they experience this type of accidents but very rarely. Reasons were that contractors don't like bearing the cost of providing the necessary requirements for a safe working environment. The same reasons lead to minimal measures regarding the same. 


\section{VII.Conclusions}

The study concluded that technical factors, skills, working environment and occupational and safety practices account for up to $23.5 \%$ of the changes in occurrence of accidents among construction sites in Nairobi as shown by an R-square of 0.235 . The study also concluded that the workers skills and experience in handling machines was negatively and significantly related to occurrence of accidents $(\mathrm{Beta}=-0.162, \mathrm{Sig}=0.042)$ and $($ Beta $=0.301$, Sig $=0.002)$ respectively at the level of significance set at $5 \%$. Based on the findings, working environment was negatively related to occurrence of accidents at construction sites surveyed in this study. The relationship was however not significant which could imply that major factors concerning the working environment are not practiced in most construction sites (Beta $=-0.015$, Sig $=0.887$ ). For instance provision of gears at the site to protect workers against continuous exposure to moderately high level of impulse noise such as explosives on site, noise produced by heavy equipment, and welding noise to prevent occupational deafness; provision of guard railing systems or other alternatives at the site to prevent mechanical hazards; construction workers at the site working under sheltered environment to avoid adverse weather conditions which could lead to discomfort and illness and optimizing of the size of workforce given the available working space and technology so as to avoid cases of over deployment in order to minimize accidents. Occupational safety and practices was negatively and significantly related to occurrence of accidents at construction sites in Nairobi County $(($ Beta $=-$ 0.301, Sig = 0.002). The occupational practices being undertaken by OHS officers were regulation of safety risk assessment in collaboration with professional bodies in development of guidelines of implementing safety programmes to be used at construction sites as agreed by $48.3 \%$ of the respondents, regulation of safety risk planning before approval of building and ensuring presentation of safety risk plan as a condition before development of a building is not practiced in the building industry in Kenya as agreed by $37.2 \%$ of the respondents .

\section{Recommendations of the Study}

The study recommends that practices concerning technical factors for instance regular maintenance of construction equipment in the standard conditions of contract at the site, quality inspection of projects and conducting regular checks so as to detect and correct faults early before they lead to accidents and reduction of the duration taken to detect rework at the site should be practiced more. The study also recommends that the building industry in Kenya should increase the frequency of practicing regular checks at the site to ensure that safe methods of work are employed, thorough audit of the abilities of contractors before they are given a contract, frequent skill audit at the site to ensure that workers have the required skills to execute work safety and conducting of trainings on the personnel and workers at the construction site in order to raise their awareness and technical knowhow on their jobs.

The study recommends that the frequency of conducting practices concerning the working environment should be increased for instance provision of gears at the site to protect workers against continuous exposure to moderately high level of impulse noise such as explosives on site noise produced by heavy equipment, welding noise etc. to prevent occupational deafness, provision of guard railing systems or other alternatives at the site to prevent mechanical hazards, construction workers at the site working under sheltered environment to avoid adverse weather conditions which could lead to discomfort and illness, optimizing of the size of workforce given the available working space and technology so as to avoid cases of over deployment in order to minimize accidents. The study recommends that there should be regulation of safety risk assessment by OHS and the government of Kenya, regulation of safety risk planning before approval of building plans is poorly done, presentation of safety risk plan as a condition before development of a building and development of standards of acceptable building densities (ratio of building are to plot size) for various categories of construction projects in Kenya.

\section{Suggested Areas for Further Study}

The study recommends that a study can be conducted in a different context other than the construction sites for instance to establish the determinants of occurrence of accidents in the manufacturing or mining sector. Furthermore, a study can be conducted to establish other factors other than those considered in this study since an R-square of $23.5 \%$ of the changes in occurrence of accidents in the building industry in Kenya is explained by technical factors, workers skills and experience, working environment and occupational safety and practices. The remaining $76.5 \%$ is explained by other factors. A study can be conducted to establish these other factors. This study was limited to low and high income areas in Nairobi County. There is a need for further studies to focus on other areas other than those investigated in this study so as to establish findings which can be comparable to this study. The findings of this study are limited to a sample of 96 respondents and hence recommendation that other studies can increase the sample size and compare the findings to that of this study in order to make more informed recommendations.

\section{References}

Abdel amid, T.S. and Everett, J.G. (2000), Identifying root causes of construction accidents. Journal of Construction Engineering and Management, 126(1), pp. 52-60. 
Adeniye A.A (2001). Health \& Safety on construction Site, Journal of Nigeria Institute of Building. Journal of Construction Engineering and Management, 8(4), 12-21

Arinaitwe, H.M., Mwakali, J.A., Hansson, B.(2007a), Factors affecting the productivity of building craftsmen-studies of Uganda. Journal of Civil Engineering and Management, 13(3), pp. 169-176.

David, W. (1998). Employee representation, health and safety: a strategy for improving health and safety performance in small enterprises? Employee Relations, Vol. 20 Issue: 2, General review.

Giang, D.T.H. and Pheng, L.S. (2011), Role of construction in economic development: review of key concepts in the past 40years. Habitat International, 35(1), pp. 118-125.

Gillen, M., Kools, S., McCalla, C., Sumb, J., and Moulden, K. (2004). “Construction managers' perceptions of construction safety practices in small and large firms: A qualitative investigation”, Work 23 233-243, IOS Press.

Haupt, T. C (2003). The research of direction's attitude to the way of worker's safety security, reasoned participating. Journal of Construction Research, Vol. 4 Issue 1, p. 87, 14 p.

Hinze, J. \& Wilson, G. (2000).Towards absolute accidents absence. Journal of Construction Engineering \& Management; Vol. 126 Issue 5, p. 399, 5p, 2 graphs.

Huang, X. \& Hinze,J (2003).“Analysis of construction worker fall accidents,” Journal of Construction Engineering and Management, vol. 129, no. 3, pp. 262-271.

Irumba, R. (2015). Modeling of Construction Safety Performance and Housing Markets in Kampala, Uganda.

Jannadi, O.A \& M. S. Bu-Khamsin, M, A.(2002)."Safety factors considered by industrial contractors in Saudi Arabia,” Building and Environment, vol. 37, no. 5, pp. 539-547.

Jaselskis E.J and Suazo, G.A.R (1994) a survey of construction site safety in Honduras. Construction Management and economics $12,245-255$.

Jimmie (2001), Introduction to Health and Safety in Construction: A Survey Project

Kadiri, Z. O., Nden, T., Avre, G. K., Oladipo, T. O., Edom, A., Samuel, P. O., \& Ananso, G. N. (2014). Causes and Effects of Accidents on Construction Sites (A Case Study of Some Selected Construction Firms in Abuja FCT Nigeria). IOSR J. Mech. Civ. Eng, 11(5), 66-72.

Kakitahi J. M., Landin, A. and Alinaitwe, H. M. (2013), An exploratory study of rework causality in Uganda. Construction Innovation, 13(3), pp. 266-280.

KNBS (2012). National population and Housing report

Lopez-Valcarcel, A. (2001), Occupational safety and health in the construction work. African Newsletter on Occupational Health and Safety, 11(1), pp. 4-7.

Lubega, H. A., Kiggundu, B. M., and Tindiwensi, D. (2000), An investigation of the causes of accidents in the construction industry in Uganda, In Proceedings of the 2nd International Conference on Construction in Developing Countries: Challenges Facing the Construction Industry in Developing Countries, 15th -17th November 2000, Gaborone, Botswana.

Maina, W. H. (2014). School of Environmental Studies (doctoral dissertation, kenyatta university).

Mwakali, J. A. (2006), A review of the causes and remedies of construction related accidents: the Uganda experience, In Proceedings of the First International Conference on Advances in Engineering and Technology, 16-19 July 2006, Entebbe, Uganda, pp. 285299.

Odetoyinbo O.A (1986). The relevance of hazard assessment and control to practioneer accident. ThesisOn building construction site pg 56, 61, 114. 
Ofori, G. (2006), Revaluing construction in developing countries: a research agenda. Journal of Construction in Developing Countries, 11(1), pp. 1-11.

Petersen, D. (1971), Techniques of safety management, McGraw Hill, New York:

Petersen, D. (1988), Safety management: a human approach. New York: Aloray, Inc.

Pheng, L. S. and Leong, C.H.Y (1992), A revisit of Turin's paradigm: construction and development in the 1970s and 1970s. Habitat International, 16(3), pp. 103-117.

Qureshi, Z.H. (2007), A Review of accident modeling approaches for complex socio-technical systems. Proceedings of Conferences in Research and Practice in Information Technology, Cant, T. (ed.), 86, Australian Computer Society.

Rahmani, A., Khadem, M., Madreseh, E., Aghaei, H. A., Raei, M., \& Karchani, M. (2013). Descriptive study of occupational accidents and their causes among electricity distribution company workers at an eight-year period in Iran. Safety and health at work, 4(3), 160-165.

Wachira, P. K. (2015). The contribution of human factors in the performance of construction projects in Kenya. Unpublished Masters Project, University of Nairobi.

Wells, J. (1985). The role of construction in economic growth and development. Habitat International, 9(1), pp. 55-70.

Wells, J. (2001), Construction and capital formation in less developed economies: unraveling the informal sector in an African city. Construction Management and Economics, 19(3), pp. 267-274.

Wilson Jr., J.M. \& Koehn,E. (2002). "Safety management: problems encountered and recommended solutions," Journal of Construction Engineering and Management, vol. 